\title{
BrightEarth project shows up dark deeds
}

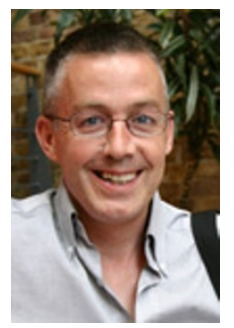

Google Farth is now being used to advocate for human rights and highlight the tragedy in Darfur, says Declan Butler.

Declan Butler

When anyone now downloads Google Earth and browses over Africa, their eye cannot escape the ongoing genocide in Darfur. The country appears to be literally on fire, with flame symbols marking the locations of more than 1,600 destroyed villages and towns in this nation the size of France.

data, documenting a conflict that has thus far killed more than 300,000 and displaced 2.3 million refugees.

The BrightEarth project, which I have been a part of since its outset in 2005, resulted from an ad-hoc collaboration between the United States Holocaust Memorial Museum in Washington, Google and a motley crew of outside volunteers (that's where I come in) including geeks, mapping experts and human-rights professionals.

It was the brainchild of Michael Graham, a research associate at the museum and an expert in international affairs. After Google Earth was launched in June 2005, he had what he describes as an 'aha!' moment, realizing that it offered a powerful new way to advance advocacy of global human rights and humanitarian issues. He was right.

Bright ideas

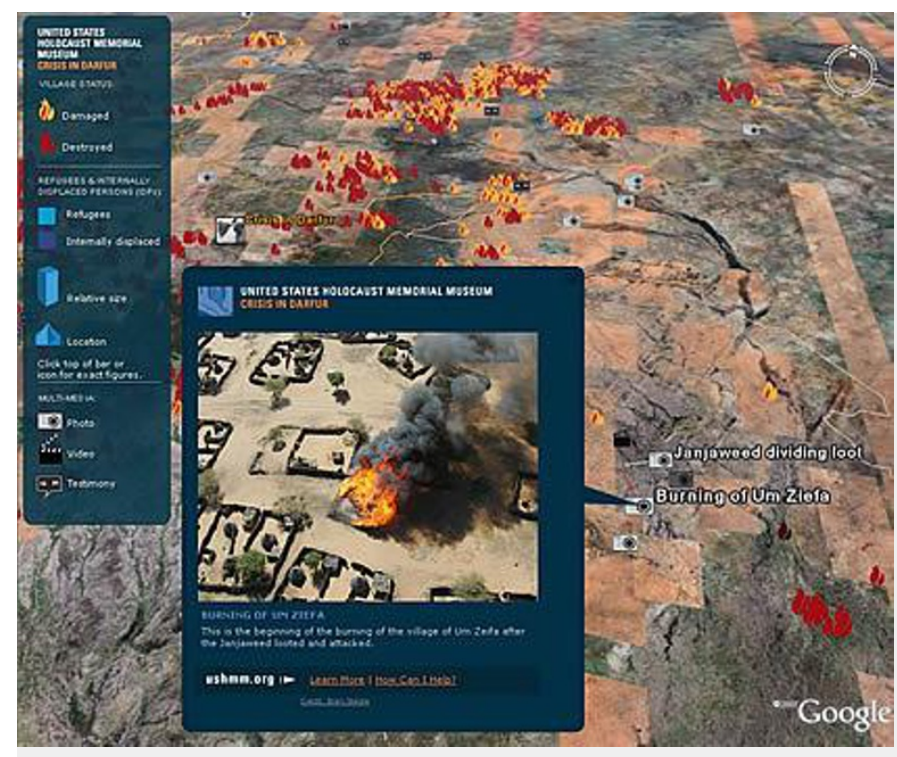

Satellite pictures and close-up photos provide an intimate look at Darfur.

Graham took his idea, dubbed 'BrightEarth', forward with backing from Matt Levinger,

the director of the museum's Academy for Genocide Prevention. Lacking funds, Graham turned to volunteers to build a proof-of-principle pilot project. A few networking emails and Skype teleconferences later, he had a small virtual team to make it work - I got involved because of my experience creating a Google Earth map of the spread of avian flu (see Nature 's Google Earth page ).

By November 2006, the team had together whipped up something impressive enough for the museum to officially adopt, host, polish and update the 'Crisis in Darfur' application (see 'Who volunteered what'). Great news, as volunteers can only do so much for so long.

Google also agreed to come on board, making the layer come up by default in new downloads of their program(the first time they have ever done that), and contributing enormously by purchasing high-resolution imagery of much of Darfur. This allows users to zoom in and see direct evidence of the genocide, with burnt huts in villages appearing as charred circles.

(There have been a few glitches with this process; if you have problems seeing all the villages in the Google Earth default layer, get your hands on the full version directly here)

\section{Spread the word}

The result has already helped hugely with public advocacy of the genocide. Its formal release on 10 April sparked worldwide media coverage. Others have perhaps found the attention less of a good thing: people in Sudan this week have found they can't get access to new downloads of Google Earth. 
But what the media hasn't much talked about is how this project is just the beginning. Graham hopes that in future, genocides might be prevented by bringing human rights abuses to life, for both the media and the international public. A Genocide Prevention Mapping Initiative, also launched by the Holocaust Memorial Museum at the same time as 'Crisis in Darfu', is considering mapping abuses in Chad, the Central African Republic and the Congo as well as the hundreds of refugee camps in Europe during the Holocaust.

"BrightEarth envisions a world in which humanitarian and human rights information is visually engaging, global in scope, and as easy to access and display on a home computer as the latest football scores," says Graham That should help human rights professionals and policy-makers as well as the general public.

"I think this is a really significant step in human-rights advocacy in the information revolution," writes humanitarian consultant Paul Currion on his blog. "Only time will tell whether we'll see more of these types of initiatives, whether they'll make a significant impact in our political dialogue, and whether that will contribute to a more peaceful world."

I can second those sentiments and hopes.

Visit our projectshowsupd.html">newsblog to read and post comments about this story. 